IJCOM 2021 July;1(1):1-2

\title{
EDITORIAL
}

\section{The Importance of Journal Publication in Community and Occupational Medicine in Indonesia}

Ray Wagiu Basrowi

The Association of Alumni of Occupational Medicine Magister Faculty of Medicine Universitas Indonesia (ILUNI MKK FKUI)

Correspondence address: Ray Wagiu Basrowi

E-mail: ray.basrowi@gmail.com

Research in community and occupational medicine field has grown rapidly in the last decade. In European countries such as Netherland, the contribution of authors in occupational health journal has even doubles in the past five years. ${ }^{1}$ Knowledge of community and occupational health medicine; which includes community, and occupational health and medicine, epidemiology, community nutrition, and health economics, is constantly growing, hence increase the need of journal submissions and reference searches. In this digital era, the role of web has greatly reduced the barriers for publishing and communicating scientific and research works outcome. ${ }^{2}$ Journals online in open access (OA) platform is one of many strategic methods with high impact and relevancy. With peer-reviewed method prior of publication, this model of publishing can be freely accessed. ${ }^{3}$

In Indonesia, there are still only few of open accessed journal publications in the field of community and occupational medicine. We understand the urge and importance of providing publication platform in this field, therefore The Association of Alumni of Occupational Medicine Magister Faculty of Medicine Universitas Indonesia (ILUNI MKK FKUI) launches The Indonesian Journal of Community and Occupational Medicine (IJCOM) as an open access journal for the expansion of community and occupational medicine-related knowledge and acts as a media for authors to publish their researches.

IJCOM is the peer-reviewed, world scale scientific journal of community, occupational clinical, and epidemiology, community nutrition, and health economics. As the official journal of ILUNI MKK FKUI we committed to facilitate 
authors, academicians, students and health care professionals to share their science work in community and occupational medicine, as well as other related field includes epidemiology, community nutrition, family medicine, health economics and other public health research works. This Journal also act as the platform to provide learnings and recommendations in community and occupational medicine and related data for the development of good health practice for Indonesian community and the world.

We do realize that this first issue is a baby step for a greater future. We will definitely put our utmost effort and energy to develop and grow this journal to meet all the requirements of national accredited journal and ultimately a reputable international journal standard.

\section{References}

1. Burdorf A. Research in occupational medicine in the Netherlands: responsiveness to societal needs, Occupational Medicine. 2010; 60(4): 242-244

2. Davis GF. Editorial Essay: Why Do We Still Have Journals? Adm Sci Q. 2014;59(2):193-201.

3. Laakso M, Welling P, Bukvova H, Nyman L, Björk B-C, Hedlund T. The Development of Open Access Journal Publishing from 1993 to 2009. HermesLima M, editor. PLoS ONE. 2011;6(6):e20961. 